\title{
AVALIAÇÃo DE MÉTODOS DE ESTRATIFICAÇÃO PARA A QUEBRA DE DORMÊNCIA DE SEMENTES DE ERVA-MATE
}

\author{
F. L. CUQUEL \\ Departamento de Fitotecnia e Filossanitarismo-UFPR, C.P. 2959, CEP: $80001-970$ - Curutiba,PR \\ M. L. M. DE CARVALHO \\ Departamento de Agricultura-UFLA, C.P. 37, CEP: 37200-000 - Lavras, MG \\ H.M.C.P. CHAMMA \\ Departamento de Agricultura-ESALQ/USP, C.P. 9, CEP: 13418-900 - Piracicaba,SP
}

\begin{abstract}
RRSUMO: Na tentativa de verificar o metodo de estratificaçăo mais adequado para a quebra de dormencia de sementes de erva mate (Ilex paraguariensis, St. Hil.), tres lotes de diferentes procedências foram submetidos, durante 6 meses, a tratamentos de estratificaçăo em ambiente năo controlado em campo e sob condiçōes variáveis de disponibilidade de lux, temperatura, ácido giberetico e de nitrato de potássio em laboratório. As avaliaçoes da porcentagem de germinaçāo foram efetuadas a cada dois meses, constatando que existem diferenças de respostas de lotes a métodos de estratificação. Os métodos de estratificação que envolveram alternância de luz e temperatura e adição de nitrato de potássio foram os mais indicados para redurir o perfodo de doméncia de sementes de erva mate.

Descritores: Ilex paraguariensis St. Hil., sementes, germinaçäo, dormência
\end{abstract}

\section{EVALUATION OF STRATTICATION METHODS FOR DORMANCY BREAK

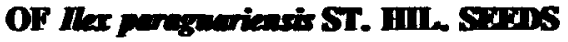

\begin{abstract}
AISTRACT: Three lots of Ilex paraguariensis St. Hi1. seeds from different origin were tested to determine the most proper stratification method to break seed dormancy. The seed lots were submitted, during six months to treatments of light and temperature alternation, addition of giberelic acid and potassium nitrate, low temperatures, and stratification in field and laboratory conditions. The evaluation of seed germination percentages were performed bimonthly. There were significative differences in the response of the seed lots to the stratification methods. The methods involving light and temperature alternation and addition of potassium nitrate were the most adequate to reduce the period of Mex paraguariensis dormancy.
\end{abstract}

Key Weris: Ilex paraguartensis St. Hil., seed, germination, dormancy

\section{INTRODUÇÃO}

A erva-mate (llex paraguariensis, $\mathrm{St}$. Hil.) e uma espécie de grande valor comercial no sul do Brasil e países limitrofes, de cujas folhas e ramos finos, secos e triturados, são preparadas bebidas feitas por infusão a quente, o "chimarrão" ou a frio, o "tererê" e das folhas tostadas preparase o "chá mate".

Atualmente a produção de erva mate é insuficiente para abastecer o mercado interno, face ao declínio da produção nos últimos anos. Entre os aspectos que levam a esta condição são determinantes, de acordo com GOULART (1978), a falta de reflorestamento que atenda a demanda, bem como as dificuldades de implantação da cultura. A obtenção de sementes pode ser considerada como o principal fator de limitação ao incentivo à atividade ervateira, quer pela escassez de matrizes, quer pelo baixo percentual de germinação das sementes obtidas (cerca de 10\%), bem como pela coleta inadequada (PROJETO ERVA-MATE 1, 1980).

Mesmo sob condições favoráveis, a semente de erva-mate recém-colhida não apresenta condições de germinar, passando por um período de repouso de ate 2 anos. Segundo MELLO (1980) ela $\hat{e}$ incapaz de germinar por apresentar embrião rudimentar, isto é, uma massa de tecido meristemático não diferenciado. As sementes desprendem-se da planta-mãe antes de estarem morfologicamente maduras, ocorrendo o término da maturação após a dispersão das mesmas (MALAVASI, 1988).

DIAPP (1984) levanta a hip6tese da existência de inibidores da germinação na semente de erva-mate, conforme já havia se referido WAREING (1965), que afirma que a dormência de 
sementes, genericamente, é função da proporção entre promotores $e$ inibidores endogenos.

CARVALHO \& NAKAGAWA (1987) consideram que a dormência de sementes resulta de um estado de equilibrio entre substâncias inibidoras da germinação, tais como o ácido abscísico e cumarina, e substâncias que estimulam a germinação, sendo a giberelina a mais importante. Para que a germinação ocorra é necessário um restabelecimento do desequilibrio favorável à giberelinas, podendo isto ocorrer pelo fornecimento de giberelina exógena. À giberelina $\epsilon$ atribuída a função de aumentar a sintese de RNA, o qual atuaria no processo de repressão genética da dormência (ROSS, 1943).

Existem diversas hipóteses que tentam explicar os problemas de dormência em sementes de erva-mate, sem contudo existirem dados consistentes que permitam chegar a conclusões definitivas. Entretanto, métodos como variações de temperatura e luz, estratificação, imersão em água, maceração ou utilização de compostos químicos, têm sido utilizados para quebra de dormência das mais variadas especies.

CARVALHO \& NAKAGAWA (1987) observaram que a aplicação de nitrato de potássio no substrato de germinação é um método amplamente recomendado; aproximadamente 26,5\% das espécies listadas nas Regras para Análise de Sementes (BRASIL, 1976) teriam sua dormência quebrada com a utilização de solução de nitrato de potássio. Os autores ainda citam que a luz tem um importante papel na quebra de dormencia devido a inibidores intemos, pois a sua ação seria a de levar o fitocromo de sua forma inativa (P660) à ativa (P730), o que liberaria ou ativaria por um processo desconhecido, as citocininas, que agindo antagonicamente em relação a vários inibidores, permitiriam às giberelinas desempenharem sua função no processo germinativo.

Temperaturas alternadas ao que tudo indica, agem sobre 0 tegumento das sementes tornando-as mais permeáveis à água e ao oxigênio, além de terem influência sobre o equilibrio entre as substâncias promotoras $e$ inibidoras da germinação (CICERO, 1986). Ja, de acordo com MALAVASI (1988), a exposição diária à ciclos alternados de temperatura pode aumentar a velocidade de germinação de muitas sementes. Para muitas espécies agrícolas, isto está associado, aparentemente, com a dormencia do embrião.

Produtores de mudas de erva-mate costumam submeter as sementes à estratificação antes do plantio. De acordo com diversos autores a técnica apresenta algumas variações, porém quase sempre consiste em alternar camadas de areia com as sementes (BRAGAGNOLO et al., 1980; CROCE, 1988; ZANON, 1988; MAZUCHOWSKI, 1989).

LABORIAU (1983) afirma que as experiências realizadas com várias especies no processo de estratificação demonstraram que deve haver a interação de 3 fatores ecológicos essenciais: temperatura, umidade e oxigennio.

0 processo de estratificação de sementes usado pelos agricultores para llex paraguariensis, possibilita algum sucesso na produção de mudas, de acordo com CUNHA \& FERREIRA (1987), porque evita seu dessecamento, ao mesmo tempo que baixa a tensão de oxigênio e aumenta a tensão de $\mathrm{CO}_{2}$. Nesse meio tempo haveria condição para maturação ou superação de bloqueios ao desenvolvimento integral do embrião.

Quanto ao armazenamento das sementes, os autores afirmam que em erva-mate, altas temperaturas aceleram a senescência, podendo ser prejudicial a maturação do embrião. Além disso a estocagem fora do fruto, em atmosfera com baixa umidade conduz rapidamente a perda da capacidade germinativa.

Visando avaliar os métodos de estratificação mais adequado quebra de dormência de sementes de erva-mate, foi realizado o presente trabalho.

\section{MATERIAL E METTODOS}

Os dados foram gerados em trabalhos de laboratório e de campo. A parte de laboratório de sementes foi realizada na Escola Superior de Agricultura "Luiz de Queiroz" da Universidade de São Paulo, em Piracicaba-SP, e a parte de campo no Viveiro de Produção de Mudas do Instituto Ambiental do Paraná-IAP em Curitiba,PR, no período de março a novembro de 1991.

Foram testadas sementes de três lotes com procedências distintas:

- União da Vitória (PR) provenientes de ervais nativos e/ou plantados, e colhidas pelo IAP.

- Guarapuava (PR) provenientes de ervais nativos e/ou plantados, e colhidos pelo IAP.

- Teixeira Soares (PR) provenientes de pomar de coleta de sementes, as quais foram colhidas pela Empresa Leão Júnior S.A. 
As sementes de União da Vitória foram colhidas por corte dos ramos de ervais com aproximadamente 15 anos, as de Guarapuava por derriça dos ramos de ervais também com aproximadamente 15 anos e as de Teixeira Soares colhidas diretamente das árvores de pomar com 9 anos de idade.

Todos os frutos foram despolpados e secos em condições ambiente e remetidos em sacos de estopa para os locais de realização dos experimentos afim de serem submetidos aos tratamentos. As sementes foram tratadas com fungicida Benlate na dosagem de $100 \mathrm{~g}$ do produto para $100 \mathrm{~kg}$ de sementes, executando-se a seguir a estratificação das mesmas, no campo e laboratório. Uma sub-amostra de cada lote não sofreu estratificação, sendo mantida em condiçães normais de ambiente (testemunha).

No viveiro, procedeu-se estratificação pelo método convencional, em caixas de madeira medindo $40 \times 50 \mathrm{~cm}$ e uma altura de $25 \mathrm{~cm}$. Intercalaram-se duas camadas de sementes, com duas camadas de areia, cada uma com $5 \mathrm{~cm}$ de espessura, recebendo como cobertura mais uma camada de $5 \mathrm{~cm}$ de areia. As caixas foram colocadas sob condições ambientais, sendo protegidas do sol pela sombra de árvores agrupadas em capoeira até o estágio onde o tegumento da semente se rompe ao ser comprimido - na prática, este estágio é conhecido como 'mata-pulga' - quando foi avaliada a germinação.

Em laboratório, a estratificação foi efetuada em caixas gerbox. Em cada gerbox foram colocados 120 cc de areia seca, uma camada de 15 $g$ de sementes de erva-mate e mais uma camada de $120 \mathrm{cc}$ de areia seca. $O$ substrato foi umedecido até atingir $60 \%$ da capacidade de campo, com água ou solução de ácido giberélico ou solução de nitrato de potássio, de acordo com os diversos tratamentos testados.

Assim, foram testados em laboratório, além da testemunha não estratificada, mantida sob condiçöes normais de ambiente, estratificações sob diversas condições:

- $\quad$ Alternância de luz e temperatura + água

- Alternância de luz e temperatura + ácido giberélico

- $\quad$ Alternância de luz e temperatura + nitrato de potássio
- $\quad$ Ausência de luz e temperatura de $5^{\circ} \mathrm{C} \pm$ $2^{\circ} \mathrm{C}$ (Geladeira)

- Ambiente interno do laboratório

A alternância de luz e temperatura foi conseguida mantendo-se os gerbox com as sementes em germinador durante 8 horas iluminadas com luz branca fluorescente a 35 graus e 16 horas de escuro à temperatura de 15 graus. As soluções de ácido giberélico e de nitrato de potássio foram preparadas conforme recomendação das Regras para Análise de Sementes (BRASIL, 1976) e adicionadas à areia.

A estratificação foi realizada por um período total de 6 meses, e a cada 2 meses eram retiradas amostras para verificação da porcentagem de germinação. Da mesma forma, de 15 em 15 dias era avaliado o ponto de rompimento do tegumento, na prática conhecido como mata-pulga e, quando este era atingido era efetuado 0 teste de germinação.

O teste de germinação foi conduzido com 2 repetições de 100 sementes por tratamento, em gerbox contendo areia umedecida com água até atingir $60 \% \mathrm{da}$ capacidade de campo, com alternância de temperatura $\left(20^{\circ} \mathrm{C}-30^{\circ} \mathrm{C}\right)$ e luz, avaliando-se plântulas aos 40 e 60 dias após instalação do teste.

Como foi verificado o desenvolvimento de fungos, os substratos foram pulverizados periodicamente com fungicida Benlate na dosagem de $15 \mathrm{~g} / \mathrm{l}$.

O delineamento experimental utilizado foi inteiramente ao acaso com duas repetições. Para a análise estatística, os dados foram transformados em arco seno raiz quadrada $x / 100 \mathrm{e}$ submetidos ao Teste Tukey em nível de 5\% de probabilidade.

\section{RESULTADOS E DISCUSSÃO}

Embora tenham sido testados seis métodos de estratificação, mais testemunha (sementes não estratificadas) e três lotes de sementes de ervamate, a análise estatística foi efetuada com dados provenientes de dois lotes e 5 métodos de estratificação, uma vez que ao final do período experimental, as sementes estratificadas e mantidas em geladeira, as não estratificadas (testemunha) e as provenientes do lote União da Vitória não germinaram.

Da mesma forma, não foi observada a germinação das sementes de nenhum dos lotes ap6s dois meses de estratificação com avaliações aos $\mathbf{4 0}$ e 60 dias. 
A TABELA 1 mostra os resultados do teste Tukey para as médias obtidas nas diferentes avaliações, para os métodos de estratificação.

TABELA 1 - Médias de germinação (\%) de sementes de erva-mate, submetidas a vários métodos de estratificação. Piracicaba, 1992.

\begin{tabular}{ll}
\hline Métodos de estratificação & Médias \\
\hline 1. Ambiente & $1,7 \mathrm{bc}$ \\
2. Alternância de luz e temperatura & $5,2 \mathrm{a}$ \\
3. $\mathrm{KNO}_{3}+$ alt. de luz e temperatura & $4,2 \mathrm{ab}$ \\
4. $\mathrm{GA}_{3}+$ alt. de luz e temperatura & $0,8 \mathrm{~cd}$ \\
5. Convencional & $0,1 \mathrm{~d}$ \\
\hline
\end{tabular}

Letras iguais na coluna não diferem entre si em nível de 95\% de confiança, pelo teste Tukey.

Pela Tabela pode-se observar que o tratamento alternância de luz e temperatura apesar de não diferir significativamente do tratamento alternância de luz c temperatura $+\mathrm{KNO}_{3}$, mostrou-se superior aos demais métodos utilizados.

Todos os métodos testados, excetuando alternância de luz e temperatura + GA3, propiciaram maior germinação que o método convencional de estratificação.

Apesar do processo convencional promover alternância de luz e temperatura, no laboratório sob condições controladas, em que havia constância do período de exposição a estes mesmos fatores, a germinação foi significativamente superior.

Estes resultados vem ressaltar a importância do papel da luz e da temperatura na quebra-dormência de várias espécies como salientaram CARVALHO \& NAKAGAWA (1987) e MALAVASI (1988).

A ação de temperaturas alternadas foi discutida por CICERO (1986), que levanta a hipótese de que essa variação provoca maior permeabilidade do tegumento das sementes a água e ao oxigênio, bem como influencia o equilíbrio entre substâncias promotoras e inibidoras da germinação.

E importante ressaltar que apenas o resfriamento das sementes a $5^{\circ} \mathrm{C} \pm 2^{\circ} \mathrm{C}$ no processo de estratificação em geladeira, não foi suficiente para possibilitar a quebra de dormência de llex paraguariensis, uma vez que as sementes de todos os lotes não germinaram.
A TABELA 2 mostra as médias de germinação nos diferentes períodos de estratificação. Aos 4 meses de estratificação não foram observadas diferenças significativas entre os tratamentos.

Apesar de observar-se uma tendência de melhores resultados para os tratamentos alternância de luz e temperatura e alternância de luz e temperatura $+\mathrm{KNO}_{3}$, no estágio de mata-pulga, esses tratamentos possibilitaram maior germinação na avaliação aos 40 dias. Já aos 60 dias, as estratificações em ambiente, altemância de luz e temperatura e alternância de luz $+\mathrm{KNO}_{3}$ apresentaram melhores resultados.

Foram observadas diferenças nas respostas dos lotes. $O$ lote proveniente de União da Vitória não apresentou germinação até o final do experimento, permanecendo com suas sementes firmes. O lote de procedência de Guarapuava mostrou-se significativamente superior ao lote de Teixeira Soares (TABELA 3) em todos períodos de estratificação e datas de avaliações do teste de germinação.

As sementes do lote de Teixeira Soares, iniciaram a germinação somente após terem passado por um determinado período de estratificação, quando então foi verificado o estágio de "matapulga" e apenas no método de estratificação sob condições de alternância de luz e temperatura (TABELA 4).

O estágio de "mata-pulga" foi alcançado aproximadamente após 5 meses de estratificação para os lotes de Teixeira Soares e Guarapuava.

A TABELA 5 mostra que as sementes do lote de Guarapuava iniciaram sua germinação a partir dos 4 meses de estratificação, já com os dados mostrando a tendência de alternância de luz e temperatura estar entre os melhores tratamentos. Os tratamentos utilizados propiciaram uma redução no período de dormência, principalmente para o lote procedente de Guarapuava, que iniciou a germinação após 4 meses de estratificação na primeira avaliação do teste de germinação, aos $\mathbf{4 0}$ dias. Conforme citado por BRAGAGNOLO et al. (1980) e MAZUCHOWSKI (1989), a estratificação pelo método convencional dura de 6 a 7 meses inciando a germinação a partir de $\mathbf{4 0}$ dias da semeadura.

De acordo com a TABELA 6, no presente trabalho, independentemente do método de estratificação, foram verificados, após os períodos de estratificação, resultados de germinação já aos $\mathbf{4 0}$ dias após a instalação do teste de germinação conduzido em laboratório; e, aos 60 dias, as médias de germinação foram de modo geral, numericamente superiores. 
TABELA 2 - Médias de germinação (\%) de sementes de erva-mate submetidas a vários métodos e períodos de estratificação, avaliadas aos 40 e 60 dias após a instalação do teste de germinação. Piracicaba, 1992.

\begin{tabular}{lcccccc}
\hline & \multicolumn{5}{c}{ Período de estrat./Avaliação de germ. } \\
\cline { 2 - 7 } Métodos de estratificação & \multicolumn{2}{c}{4 meses } & \multicolumn{2}{c}{5 meses } & \multicolumn{2}{c}{6 meses } \\
& 40 dias & 60 dias & 40 dias & 60 dias & 40 dias & 60 dias \\
\hline 1. Ambiente & $0,3 \mathrm{a}$ & $2,8 \mathrm{a}$ & $0,0 \mathrm{~b}$ & $5,8 \mathrm{a}$ & $0,2 \mathrm{a}$ & $7,5 \mathrm{a}$ \\
2. Alternância de luz e temperatura & $4,0 \mathrm{a}$ & $4,5 \mathrm{a}$ & $6,2 \mathrm{a}$ & $8,7 \mathrm{a}$ & $1,7 \mathrm{a}$ & $7,1 \mathrm{a}$ \\
3. $\mathrm{KNO}_{3}+$ alt. de luz e temperatura & $1,6 \mathrm{a}$ & $2,2 \mathrm{a}$ & $5,0 \mathrm{a}$ & $5,7 \mathrm{a}$ & $4,0 \mathrm{a}$ & $8,4 \mathrm{a}$ \\
4. $\mathrm{GA}_{3}+$ alt. de luz e temperatura & $0,4 \mathrm{a}$ & $0,7 \mathrm{a}$ & $0,2 \mathrm{~b}$ & $0,2 \mathrm{~b}$ & $2,5 \mathrm{a}$ & $2,5 \mathrm{a}$ \\
5. Convencional & $0,0 \mathrm{a}$ & $0,0 \mathrm{a}$ & $0,0 \mathrm{~b}$ & $0,0 \mathrm{~b}$ & $0,0 \mathrm{a}$ & $3,8 \mathrm{a}$ \\
\hline \hline
\end{tabular}

As médias seguidas de letras iguais nas colunas não diferem entre si em nível de $95 \%$ de confiança, pelo teste Tukey.

- Período de estratificação após o qual foi verificado o estágio de "mata-pulga" - ponto de rompimento do tegumento ao ser comprimido.

TABELA 3 - Médias de germinação (\%) de dois lotes de sementes de erva-mate, obtidas após três períodos de estratificação e avaliadas aos 40 e 60 dias após a instalação do teste de germinação. Piracicaba, 1992.

\begin{tabular}{lccc}
\hline \multicolumn{2}{c}{ Período de estratificação / } & \multicolumn{2}{c}{ Lotes } \\
\cline { 2 - 4 } Avaliação de germinação & 40 dias & Guarapuava & Teixeira Soares \\
\hline \multirow{2}{*}{4 meses } & 60 dias & $3,1 \mathrm{a}$ & $0,0 \mathrm{~b}$ \\
& & $5,9 \mathrm{a}$ & $0,0 \mathrm{~b}$ \\
& 40 dias & & $0,0 \mathrm{~b}$ \\
5 meses & 60 dias & $4,3 \mathrm{a}$ & $0,0 \mathrm{~b}$ \\
& 40 dias & $9,5 \mathrm{a}$ & $0,1 \mathrm{~b}$ \\
60 dias & $3,8 \mathrm{a}$ & $0,4 \mathrm{~b}$ \\
\hline \hline
\end{tabular}

As médias seguidas de letras iguais nas colunas não diferem entre si em nível de $95 \%$ de confiança, pelo teste Tukey.

- Período de estratificação após o qual foi verificado o estágio de "mata-pulga" - ponto de rompimento do tegumento ao ser comprimido. 
TABELA 4 - Médias de germinação (\%) de sementes de erva-mate, dentro do lote Teixeira Soares, submetidas a vários métodos e períodos de estratificação, avaliadas aos 40 e 60 dias após a instalação do teste de germinação. Piracicaba, 1992.

\begin{tabular}{lcccccc}
\hline \hline & \multicolumn{5}{c}{ Período de estrat./Avaliação de germ. } \\
\cline { 2 - 7 } Métodos de estratificação & \multicolumn{2}{c}{4 meses } & \multicolumn{2}{c}{5 meses } & \multicolumn{2}{c}{6 meses } \\
& 40 dias & 60 dias & 40 dias & 60 dias & 40 dias & 60 dias \\
\hline 1. Ambiente & $0,0 \mathrm{a}$ & $0,0 \mathrm{a}$ & $0,0 \mathrm{a}$ & $0,0 \mathrm{a}$ & $0,0 \mathrm{a}$ & $0,8 \mathrm{a}$ \\
2. Alternância de luz e temperatura & $0,0 \mathrm{a}$ & $0,0 \mathrm{a}$ & $0,0 \mathrm{a}$ & $0,8 \mathrm{a}$ & $0,8 \mathrm{a}$ & $1,5 \mathrm{a}$ \\
3. $\mathrm{KNO}_{3}+$ alt. de luz e temperatura & $0,0 \mathrm{a}$ & $0,0 \mathrm{a}$ & $0,0 \mathrm{a}$ & $0,0 \mathrm{a}$ & $0,0 \mathrm{a}$ & $0,8 \mathrm{a}$ \\
4. $\mathrm{GA}_{3}+$ alt. de luz e temperatura & $0,0 \mathrm{a}$ & $0,0 \mathrm{a}$ & $0,0 \mathrm{a}$ & $0,0 \mathrm{a}$ & $0,0 \mathrm{a}$ & $0,0 \mathrm{a}$ \\
5. Convencional & $0,0 \mathrm{a}$ & $0,0 \mathrm{a}$ & $0,0 \mathrm{a}$ & $0,0 \mathrm{a}$ & $0,0 \mathrm{a}$ & $0,0 \mathrm{a}$ \\
\hline \hline
\end{tabular}

As médias seguidas de letras iguais nas colunas não diferem entre si em nível de $95 \%$ de confiança, pelo teste Tukey.

- Periodo de estratificação após o qual foi verificado o estágio de "mata-pulga" - ponto de rompimento do tegumento ao ser comprimido.

TABELA 5 - MÉdias de germinação (\%) de sementes de erva-mate, dentro do lote Guarapuava, submetidas a vários métodos e períodos de estratificação, avaliadas aos 40 e 60 dias após a instalação do teste de germinação. Piracicaba, 1992.

\begin{tabular}{lcccccc}
\hline \hline & \multicolumn{5}{c}{ Período de estrat./Avaliação de germ. } \\
\cline { 2 - 7 } Métodos de estratificação & \multicolumn{2}{c}{4 meses } & \multicolumn{2}{c}{5 meses } & \multicolumn{2}{c}{6 meses } \\
& 40 dias & 60 dias & 40 dias & 60 dias & 40 dias & 60 dias \\
\hline 1. Ambiente & $1,0 \mathrm{a}$ & $11,0 \mathrm{a}$ & $0,0 \mathrm{~b}$ & $22,0 \mathrm{a}$ & $0,8 \mathrm{a}$ & $20,4 \mathrm{a}$ \\
2. Alternância de luz e temperatura & $15,5 \mathrm{a}$ & $17,9 \mathrm{a}$ & $23,4 \mathrm{a}$ & $23,9 \mathrm{a}$ & $3,1 \mathrm{ab}$ & $16,4 \mathrm{a}$ \\
3. $\mathrm{KNO}_{3}+$ alt. de luz e temperatura & $6,4 \mathrm{a}$ & $8,5 \mathrm{a}$ & $12,1 \mathrm{a}$ & $21,6 \mathrm{a}$ & $15,3 \mathrm{a}$ & $23,0 \mathrm{a}$ \\
4. $\mathrm{GA}_{3}+$ alt. de luz e temperatura & $1,5 \mathrm{a}$ & $2,6 \mathrm{a}$ & $0,8 \mathrm{~b}$ & $0,8 \mathrm{~b}$ & $9,8 \mathrm{ab}$ & $9,8 \mathrm{a}$ \\
5. Convencional & $0,0 \mathrm{a}$ & $0,0 \mathrm{a}$ & $0,0 \mathrm{~b}$ & $0,0 \mathrm{~b}$ & $0,0 \mathrm{~b}$ & $14,5 \mathrm{a}$ \\
\hline \hline
\end{tabular}

As médias seguidas de letras iguais nas colunas não diferem entre si em nível de $95 \%$ de confiança, pelo teste Tukey.

- Período de estratificação após o qual foi verificado o estágio de "mata-pulga" - ponto de rompimento do tegumento ao ser comprimido. 
TABELA 6 - Médias de germinação (\%) de sementes de erva-mate, obtidas após três períodos de estratificação e avaliadas aos 40 e 60 dias após a instalação do teste de germinação. Piracicaba, 1992.

Período de estratificação/

Germinação (\%)

Avaliação de germinação

\begin{tabular}{lll}
\hline 4 meses & 40 dias & $0,8 \mathrm{~b}$ \\
& 60 dias & $1,5 \mathrm{~b}$ \\
5 meses & 40 dias & $1,1 \mathrm{~b}$ \\
& 60 dias & $2,7 \mathrm{ab}$ \\
6 meses & 40 dias & $1,1 \mathrm{~b}$ \\
& 60 dias & $5,6 \mathrm{a}$ \\
\hline
\end{tabular}

As médias seguidas de letras iguais nas colunas não diferem entre si em nível de $95 \%$ de confiança, pelo teste Tukey.

- Período de estratificação após o qual foi verificado o estágio de "mata-pulga" - ponto de rompimento do tegumento ao ser comprimido.

\section{CONCLUSÕES}

- Os métodos de estratificação que envolveram alternância de luz e temperatura e adição de nitrato de potássio foram os mais indicados para reduzir o período de dormência de sementes de erva-mate.

- Existem diferenças de respostas de lotes de ervamate a métodos de estratificação.

- O ponto de rompimento do tegumento ao ser comprimido, na prática conhecido como "matapulga", é um bom referencial para indicar a quebra de dormência.

\section{AGRADECIMENTOS}

Às colegas Engenheiras Agrônomas Ana D.C. Novembre e Denise F.C.S. Dias pela colaboração na execução deste trabalho.

\section{REFERÊNCIAS BIBLIOGRÁFICAS}

BRAGAGNOLO, N.; PAN, W.; KLOSOVSKI FILHO, D. Manual tecnico da erva-mate. Curitiba: EMATER-PR, 1980. 40p.
BRASIL. Ministério da Agricultura. Regras para Andilise de Sementes. Brasília: LANARV, SNAD, 1976. 183p.

CARVALHO, N.M.; NAKAGAWA, J. Sementes: ciência, tecnologia e produção.3.Ed. Campinas: Fund. Cargill, 1987. 424p.

CICERO, S.M. Dormência de sementes. In: SEMANA DE ATUALIZAÇĀO EM PRODUÇÃO DE SEMENTES, 1., 1986, Piracicaba. Trabalhos apresentados... Campinas: Fundação Cargill, 1986. p.41-73.

CROCE, D.M. Pesquisa com erva-mate. Agropecuária Catarinense, Florianópolis, v.1, n.2, p.10-11, 1988.

CUNHA, G.G.; FERREIRA, A.G. Viabilidade de sementes de erva-mate. Ciência e Cultura, São Paulo, v.39, n.10, p.974-976, 1987.

DIAPP, C.J. Espermo-anatomia e período de crescimento do embrião de llex paraguariensis St. Hil. Dusenia, Curitiba, v.14, n.3, p.113-121, 1984.

GOULART, L.M. Diagnóstico da cultura de erva-mate no Brasil. Brasília: IBDF, COPLAN, 1978. 73p.

LABORIAU, L.G. A germinação das sementes. Washington, OEA, 1983. 174p.

MALAVASI, M.M. Germinação de sementes. In: RODRIGUES, F.M.C. Manual de anślise de sementes Alorestais. Campinas: Fundação Cargill, 1988. p.25-40.

MAZUCHOWSKI, J. A cultura da erva-mate. Curitiba: EMATER-PR, 1989.36p.

MELLO, V.D.C. Morfologia e germinação da semente de erva-mate (llex paraguariensis St. Hil.). Pelotas, 1980. 81p. Dissertação (M.S) - Universidade Federal de Pelotas.

PROJETO ERVA-MATE 1. Brasil Madeira, Curitiba, v.4, n.48, p.25-26, 1980.

ROSS, J.D. Metabolic aspects of dormancy. In: MURRAY, D.R. Seed physiology, 2.Ed. Melbourne, CRC PRESS, 1943. p.45-75

WAREING, P.F. Endogenous inhibitors of seeds germination and dormancy. Encyclopedia of Plant Physiology, New York, v.15, n.2, p.909-922, 1965.

ZANON, A. Produçáo de sementes de erva-mate. Curitiba: EMBRAPA, CNPF, 1988. 7p. (EMBRAPA/CNPAF. Circular Técnica, 16).

Recebido para publicação em 03.05.93

Aceito para publicação em 09.11 .94 